\title{
METÁSTASE DE CARCINOMA MAMÁRIO EM SISTEMA NERVOSO CENTRAL DE CADELA
}

Mariana Ribeiro de Castro ${ }^{1}$, Bethânia Almeida Gouveia ${ }^{2}$, Marina Carla Bezerra da Silva $^{2}$, Alessandra Aparecida Medeiros-Ronchi ${ }^{3}$, José Eugênio Diniz Bastos ${ }^{4}$

1- Médica Veterinária, Residente do Programa de Residência Multiprofissional em Saúde, área de Patologia Animal da Universidade Federal de Uberlândia (marianarc4@hotmail.com), Uberlândia - Brasil.

2- Discente da Faculdade de Medicina Veterinária da Universidade Federal de Uberlândia.

3- Professor doutor em Patologia Animal da Universidade Federal de Uberlândia.

4- Prof. mestre em Clínica Médica de Pequenos Animais da Universidade Federal de Uberlândia.

Recebido em: 02/10/2017 - Aprovado em: 21/11/2017 - Publicado em: 05/12/2017 DOI: 10.18677/EnciBio_2017B41

\begin{abstract}
RESUMO
Metástases de carcinoma mamário podem ocorrer em vários tecidos, porém são incomuns no sistema neural. Objetivou-se relatar um caso de neoplasia mamária primária com metástase no cérebro, cerebelo, pulmão e linfonodo. $O$ animal em questão era uma cadela da raça Shih-Tzu de sete anos de idade, com histórico de neoplasia mamária com recidiva após exérese cirúrgica. O diagnóstico da neoplasia mamária foi carcinoma tubular com êmbolos neoplásicos em vasos linfáticos e metástase em linfonodo. Após a exérese cirúrgica a cadela retornou para atendimento apresentando sintomatologia compatível com síndrome vestibular. Foi realizada a eutanásia e durante a necropsia observou-se massa no lobo caudal do pulmão direito, assim como aderência da dura-máter no osso temporal e occipital, na região do hemisfério cerebral direito e cerebelo, respectivamente. Após retirada do encéfalo e cerebelo verificou-se presença de duas massas localizadas no encéfalo e cerebelo, respectivamente. A massa localizada no encéfalo direito adentrava a substância branca, apresentava coloração pardacenta, bordas ligeiramente irregulares, medindo aproximadamente $2,5 \mathrm{~cm}$ de diâmetro, em contrapartida, a massa no cerebelo era elevada, brancacenta, de formato irregular, medindo aproximadamente 2,0 cm de diâmetro. Microscopicamente havia áreas multifocais, circunscritas, de proliferação de células epiteliais, formando ácinos, compatíveis com metástase de carcinoma mamário. As metástases pulmonares de carcinoma mamário são comuns, porém infrequentes no sistema neural. No caso em questão os sinais neurológicos apresentados pelo animal foram ocasionados pela metástase de carcinoma mamário reforçando a necessidade de diagnóstico precoce e acompanhamento de cadelas portadoras de tumores de mama, mesmo após a exérese cirúrgica.
\end{abstract}

PALAVRAS-CHAVE: canino, disseminação, neoplasia mamária. 


\title{
METASTASIS OF MAMMARY CARCINOMA IN THE CENTRAL NERVOUS SYSTEM IN FEMALE DOG
}

\begin{abstract}
Metastasis of mammary carcinoma in neural system are uncommon. The goal of this study was to report a case of cerebral, cerebbelar pulmonary and limph node metastasis of primary mammary neoplasia. The animal reported was a Shih-Tzu female dog, seven years old, with history of breast cancer with recurrence after surgical excision. The diagnose of the histological type was Tubular Carcinoma Grade II with linfatic invasion. The bitch returned to the hospital with neurological signs compatible with vestibular syndrome. After that, euthanasia was performed and during the necropsy was noted mass in the caudal lobe of the right lung, adhesion of the duramater in the ventral region of the temporal and occipital bone, in the region of the right cerebral hemisphere and in the region of the cerebellum verne, respectively. After removal of the brain and cerebellum there were two masses located in the brain and cerebellum, respectively. The mass located in the right hemisphere of the brain entered the white matter, had a brownish coloration, with irregular borders, measuring approximately $2.5 \mathrm{~cm}$ in diameter, in contrast, the mass in the cerebellum was high, whitish, irregular, measuring approximately $2.0 \mathrm{~cm}$ of diameter. Microscopically had multifocal, circumscribed areas of epithelial cells proliferation, forming acini, compatible with mammary carcinoma metastasis. Pulmonary metastases of breast carcinoma are common but infrequent in the neural system. In this case, the neurological signs presented by the animal were caused by the metastasis of mammary carcinoma, reinforcing the necessity for early diagnosis and follow up of bitches with breast cancer, even after surgical excision.
\end{abstract}

KEYWORDS: canine, dissemination, mammary tumour.

\section{INTRODUÇÃO}

Com o aumento da longevidade dos cães domésticos houve também um aumento na população de cães idosos, resultando em aumento da frequência de doenças crônicas, como as neoplasias (DE NARDI et al., 2002). Os tumores de mama são frequentes em cadelas e representam aproximadamente $52 \%$ de todas as neoplasias nessa espécie, sendo que mais de $75 \%$ dos casos são considerados malignos (CASSALI et al., 2014).

Em cadelas a prevalência de neoplasias mamárias é três vezes maior que em mulheres (MISDORP, 2002). A mortalidade associada a tumores de mama relaciona-se principalmente com a presença de metástases, encontradas especialmente em linfonodos regionais e pulmões, mas também podem ser observadas metástases em baço, fígado, pele, encéfalo, rins e ossos (DE NARDI et al., 2016). Dessa maneira, dentre as neoplasias epiteliais, o carcinoma mamário é o que propicia um maior número de metástases em cadelas (LABELLE; LABELLE, 2013).

Segundo Gómez et al. (2012) cerca de 16,5\% dos carcinomas mamários apresentaram metástases pulmonares e 30\% comprometimento dos linfonodos em cadelas. Em humanos, o carcinoma mamário é a segunda neoplasia que mais apresenta metástases para o sistema nervoso central, localizando-se na maioria das vezes nos hemisférios cerebrais (SANTOS et al., 2003). Em cadelas, metástases de neoplasmas mamários ocorrem por disseminação hematógena 
(SANTOS ; ALESSI, 2017) e podem gerar pontos metastáticos em vários tecidos além de pulmão (KOESTNER; HIGGINS, 2002).

O presente estudo teve como objetivo relatar o caso de uma cadela atendida no Hospital Veterinário da Universidade Federal de Uberlândia com suspeita de síndrome vestibular associada a metástase de carcinoma mamário em sistema nervoso central.

\section{RELATO DE CASO}

Uma cadela fêmea, da raça Shih-Tzu, de cinco anos de idade foi atendida no setor de Clínica Médica de Pequenos Animais do Hospital Veterinário da Universidade Federal de Uberlândia (HV-UFU), em setembro de 2014, apresentando nódulo de $4,0 \mathrm{~cm}$ de diâmetro na mama inguinal esquerda. Foi instituído tratamento cirúrgico para retirada do nódulo por meio de mastectomia unilateral esquerda. Fragmentos do nódulo foram avaliados histologicamente e diagnosticou-se carcinoma tubular grau II, com êmbolos neoplásicos em vasos linfáticos e metástase em linfonodo inguinal.

Vinte meses após a exérese cirúrgica, o animal foi encaminhado novamente ao HV-UFU apresentando sintomatologia neurológica grave, tal como desequilíbrio, andar em círculos para o lado direito, cabeça inclinada lateralmente e convulsões, em um curso de 12 dias, além de apresentar vocalização excessiva e dificuldade para se levantar.

Ao exame físico observou-se mucosas normocoradas, respiração toracoabdominal, linfonodos submandibulares aumentados de volume e tártaro. Como exames complementares foram realizados hemograma e exame radiográfico de tórax nas posições látero-lateral e dorso-ventral. $O$ animal não apresentou alterações hematológicas e no exame de imagem detectou-se áreas radiopacas maiores que 5,0 mm de diâmetro distribuídas por todo o parênquima pulmonar.

As suspeitas clínicas foram de síndrome vestibular, toxoplasmose, neosporose, síndrome cerebelar ou metástase de carcinoma mamário em cérebro. Como o animal apresentou severo quadro clínico e neurológico, sem expectativa de melhora, foi submetido à eutanásia e encaminhado ao setor de Patologia Animal para realização de necropsia, com registro fotográfico das alterações macroscópicas e coleta de fragmentos para avaliação histológica.

\section{RESULTADOS E DISCUSSÃO}

Ao exame necroscópico observou-se nódulo na mama inguinal direita, firme, ligeiramente irregular e coloração brancacenta ao corte. Queiroga e Lopes (2002) e Rocha e Tostes (2005) verificaram que a maioria das neoplasias mamárias acometem as mamas inguinais, assim como descrito neste caso.

Detectou-se também massa de aproximadamente $3,0 \mathrm{~cm}$ localizada no lobo caudal do pulmão direito, arredondada, firme, elevada e de coloração pardacenta com centro avermelhado (Figura 1 - A), além de outros nódulos de aspecto semelhante menores que $3,0 \mathrm{~cm}$ de diâmetro distribuídos pelo parênquima pulmonar.

Durante a retirada do encéfalo notou-se áreas de aderência entre a dura máter e osso temporal na região do hemisfério cerebral direito. Havia ainda aderência entre a dura máter e osso occipital, na região do cerebelo. Após retirada do encéfalo da caixa craniana, a região que era recoberta pela dura-máter aderida ao osso temporal apresentava-se pardacenta, firme, de aspecto maciço e ao corte 
ocupava parte do hemisfério cerebral direito, de formato irregular, medindo aproximadamente $2,5 \mathrm{~cm}$ de diâmetro. Havia ainda no cerebelo massa elevada, firme, brancacenta, irregular, medindo aproximadamente $2,0 \mathrm{~cm}$ de diâmetro (Figura 1 - B). Foram coletados fragmentos de pulmão, encéfalo e cerebelo que foram fixados em formol $10 \%$ tamponado, por 48 horas, para confecção de lâminas histológicas coradas em hematoxilina e eosina.
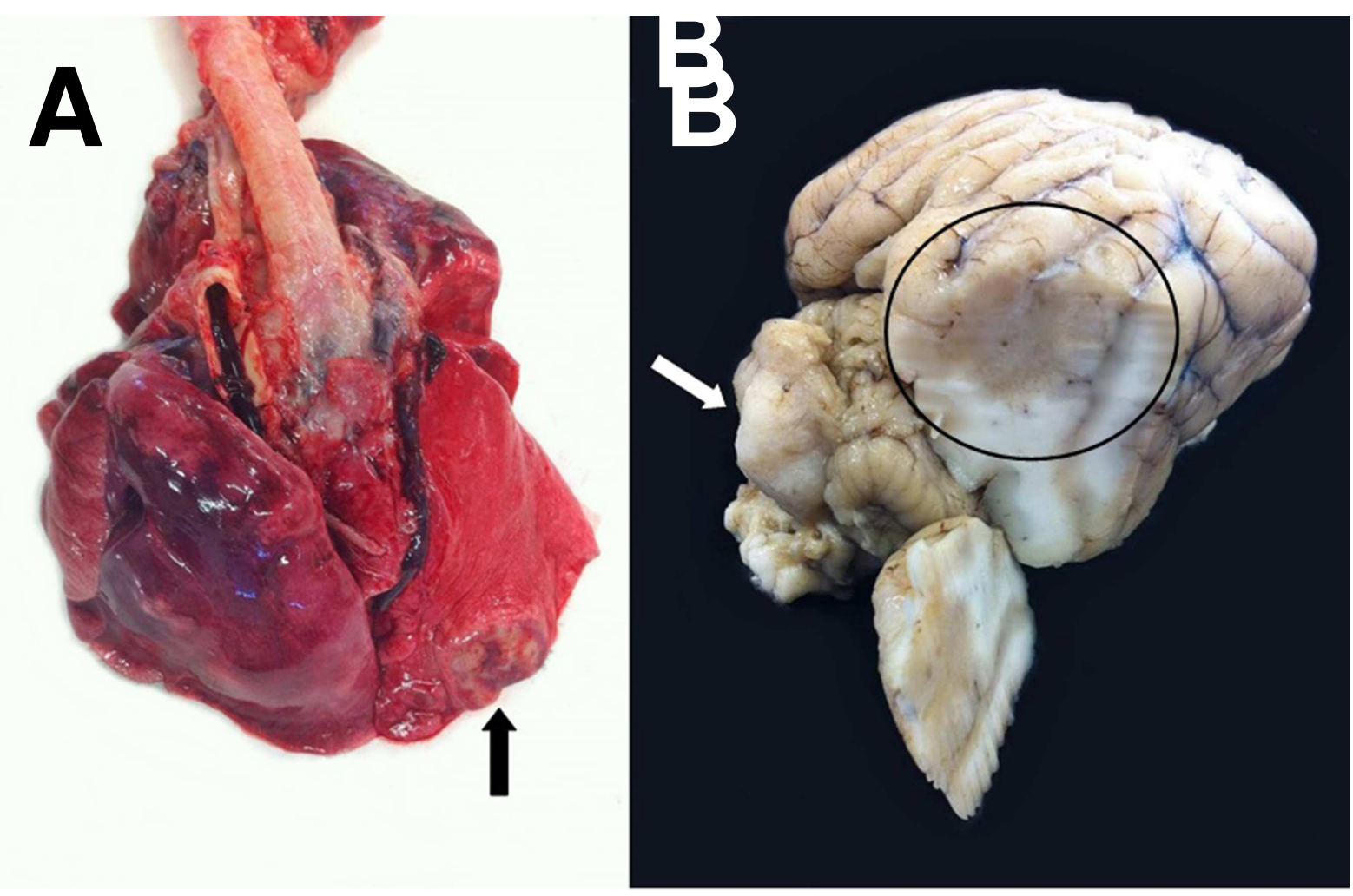

FIGURA 1. Metástase de carcinoma mamário no sistema nervoso central e pulmão de cadela Shih-Tzu. (A) Massa no lobo caudal do pulmão direito (seta preta). (B) Sistema nervoso central com área pálida no encéfalo direito (círculo preto) e cerebelo com massa elevada brancacenta (seta branca). Fonte: Arquivo pessoal.

Histologicamente no nódulo mamário observou-se áreas de proliferação de células epiteliais, arranjadas em túbulos, ocupando $50 \%$ do campo. As células neoplásicas apresentavam citoplasma amplo, levemente eosinofílico, com núcleo central e nucléolo evidente, por vezes múltiplos. Observou-se moderado pleomorfismo, com discreta anisocitose e anisocariose e raras figuras de mitose (entre 1 e 8 figuras de mitose atípicas por campo de grande aumento - CGA) (Figura 2 A). Estas características são compatíveis com carcinoma tubular grau II.

$\mathrm{Na}$ análise histológica, as massas encontradas no pulmão, cérebro e cerebelo possuíam características microscópicas semelhantes às observadas no nódulo mamário, sendo formadas por proliferação de células epiteliais, arranjadas em túbulos, por vezes com grandes áreas centrais de necrose, características de metástase de carcinoma mamário (Figura 2 B). 


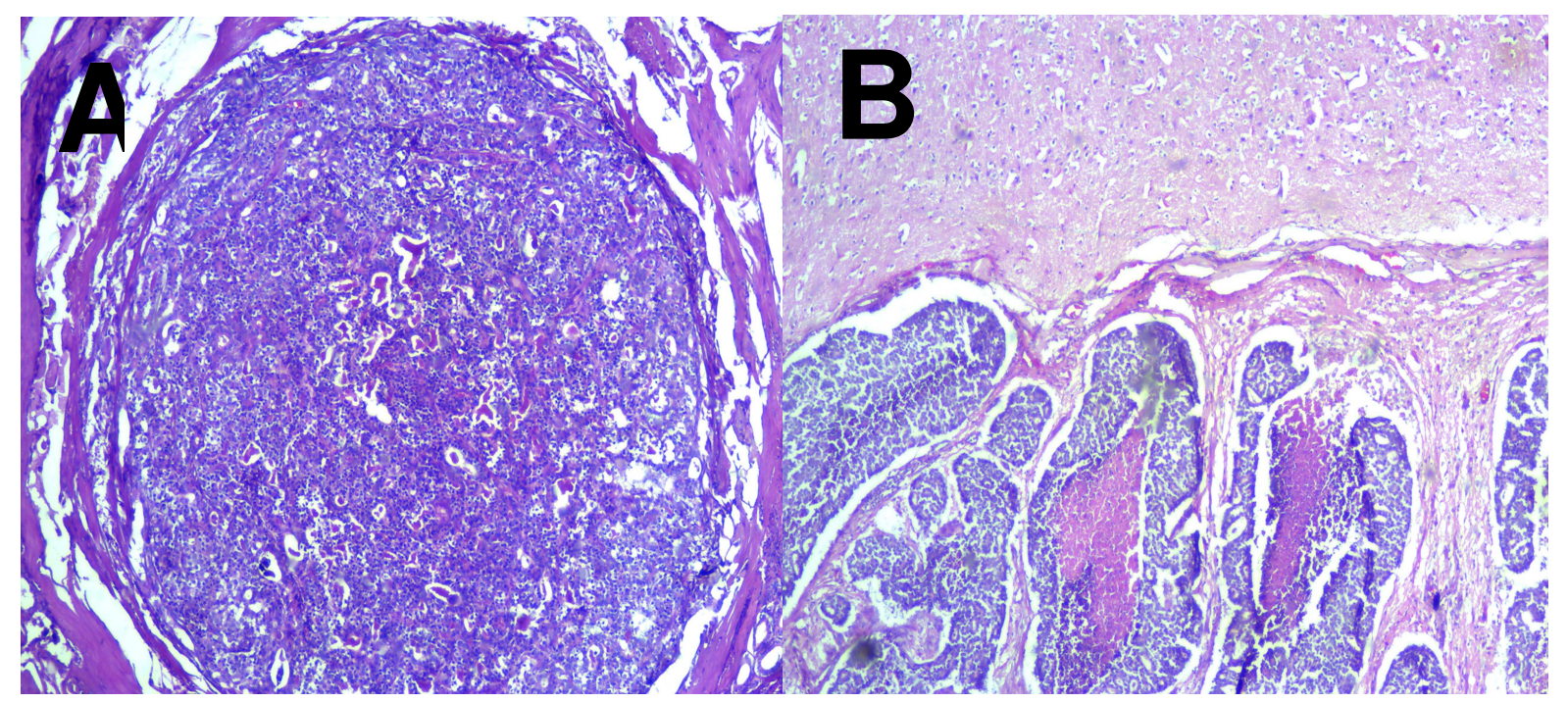

FIGURA 2. Fotomicrografias de carcinoma tubular e metástase de carcinoma mamário no sistema nervoso central de cadela Shih-Tzu. (A) Fragmento de mama inguinal direita com carcinoma tubular grau II. Área de proliferação de células epiteliais arranjadas em túbulos. (B) Fragmento de encéfalo com metástase de carcinoma mamário. Infiltrando o tecido nervoso área com proliferação de células epiteliais neoplásicas, com centro necrótico. Fonte: Arquivo pessoal.

Trata-se de um caso de recidiva de carcinoma tubular grau II, com metástase em pulmão, encéfalo e cerebelo. O carcinoma tubular é uma neoplasia maligna simples comum em cadelas, com organização tubular, pleomorfismo nuclear variável, com marginação da cromatina. O estroma é composto por vasos e fibroblastos, e por vezes infiltrado de células inflamatórias como plasmócitos, macrófagos e linfócitos (GOLDSCHMIDT et al., 2017).

Misdorp (2002), comparando a malignidade entre carcinomas mamários, relata que os carcinomas simples apresentam maior malignidade quando comparados aos carcinomas complexos, e que dentre os carcinomas simples o grau de malignidade aumenta do carcinoma anaplásico para o sólido e depois o tipo tubulopapilar. No presente relato, o carcinoma tubular, desde o primeiro diagnóstico já apresentava características de malignidade, como a metástase em linfonodo inguinal. Rasotto et al. (2012) verificaram que $60 \%$ dos carcinomas tubulares apresentaram invasão linfática e $27 \%$ metástase em linfonodos.

Na primeira ocorrência do carcinoma mamário, a glândula inguinal esquerda foi acometida e na recidiva a mama inguinal direita. Os carcinomas mamários realizam metástase preferencialmente por via linfática (GOLDSCHMIDT et al., 2017). Em cadelas com glândulas mamárias normais há comunicação entre vasos linfáticos das glândulas ipsilaterais. Porém no caso da mama ser acometida por neoplasias mamárias a drenagem linfática pode ser modificada e ocorrer comunicação contralateral de vasos linfáticos (PATSIKAS et al., 1996). Provavelmente foi o que ocorreu nas mamas inguinais da cadela em questão, que apresentou recidiva na mama inguinal direita após caso de carcinoma tubular na mama inguinal esquerda. 
O grau do tumor é uma das formas de avaliação prognóstica, sendo que a cadela deste trabalho apresentava carcinoma tubular grau II. De acordo com Rasotto et al. (2012) os carcinomas tubulares são mais frequentemente do tipo II (62\%). Carcinomas tubulares grau II apresentam invasão linfovascular em $71 \%$ dos casos e metástase para os linfonodos em $31 \%$ dos casos. O percentual de invasão linfovascular e metástase em linfonodos é maior no caso de tumores grau III $(83 \%$ e $67 \%$ respectivamente).

De acordo com Kwiecien et al. (2017) os carcinomas mamários possuem um fator de transcrição (kaiso), que uma vez expresso determina características agressivas que se relacionam com o processo de metástase, como a formação de êmbolos neoplásicos. Estes êmbolos se destacam do tumor primário e frequentemente se alojam no pulmão, obedecendo ao fluxo sanguíneo (ROUSSOS et al., 2011). Este mecanismo provavelmente está envolvido na metástase pulmonar identificada no caso.

Metástases cerebrais de tumores mamários são comumente relatadas na espécie humana, entretanto são escassos os relatos em cadelas. Segundo Azim et al. (2017), em mulheres, há maior risco de ocorrer metástase cerebral quando já ocorreu metástase pulmonar; e outros fatores que também podem influenciar são o menor intervalo de recidiva e expressão de HER2 (receptor do fator de crescimento epidérmico humano tipo 2). Em animais domésticos, Higgins et al. (2017) apontaram os carcinomas nasal, pulmonar, mamário e renal como aqueles que apresentaram sítios de metástase no sistema nervoso central mais frequentemente. No presente caso o animal apresentou inicialmente metástase em linfonodo e, posteriormente, metástase pulmonar e cerebral.

A cadela em questão apresentou recidiva com sinais neurológicos 20 meses após a exérese cirúrgica do carcinoma tubular. Rasotto et al. (2017) relataram que cadelas com carcinoma tubular apresentaram taxa de sobrevivência de $93 \%$ após um ano, dado semelhante ao apresentado neste relato após o diagnóstico do mesmo tipo histológico. Estes autores relatam ainda que o carcinoma tubular apresenta baixa frequência (20\%) de metástases a longa distância, ocorrendo raramente.

Rasotto et al. (2017) também avaliaram sobrevida após um e dois anos em relação a presença de invasão linfática. Verificaram que dentre as cadelas que apresentaram invasão linfática, 19\% estavam vivas após 12 meses e nenhuma após 24 meses. Neste caso, a cadela superou o primeiro ano de sobrevida mesmo com presença de invasão linfática. Porém aos 20 meses, apresentava metástase em sistema neural com grave quadro clínico e foi eutanasiada, dificultando a avaliação da sobrevida em 24 meses.

\section{CONCLUSÃO}

Metástases de tumores mamários para o sistema nervoso central são raras em cadelas e representam o estágio final do curso da doença. Este caso reforça a necessidade de um acompanhamento oncológico atencioso em quadros de neoplasias mamárias com invasões linfáticas e recidivas, mesmo após exérese cirúrgica. Deve-se incluir o diagnóstico diferencial de metástase cerebral em cadelas com sinais neurológicos e histórico de carcinoma mamário. 


\section{REFERÊNCIAS}

AZIM, H. A.; ABDEL-MALEK, R.; KASSEM, L. Predicting Brain Metastasis in Breast Cancer Patients: Stage Versus Biology. Clinical Breast Cancer, 2017. Disponível em: http://www.clinical-breast-cancer.com/article/S1526-8209(17)30235-5/fulltext DOI: http://dx.doi.org/10.1016/j.clbc.2017.08.004.

CASSALI G.D.; LAVALLE G.E.; FERREIRA E.; ESTRELA-LIMA A.; DE NARDI A.B.; GHEVER C.; et al., .Consensus for the diagnosis, prognosis and treatment of canine mammary tumors. Brazilian Journal Veterinary Pathology. V. 7, n. 2, p. 38-69, 2014. Disponível em: http://revistas.bvs-vet.org.br/bjvp/article/view/30493/33252.

DE NARDI, A. B.; RAPOSO-FERREIRA, T. M. M.; ASSUNÇÃO, K. A. Neoplasias mamárias. In: Daleck, R.C.; De Nardi, A. B. Oncologia em cães e gatos. 2 ed. São Paulo: Roca, p. 499-516, 2016.

DE NARDI, A.B.; RODASKI, S.; SOUSA, R.S. Prevalência de neoplasias e modalidades de tratamento em cães, atendidos no hospital veterinário da Universidade Federal do Paraná. Archives of Veterinary Science, v.7, p.15-26, 2002. Disponível em: http://revistas.ufpr.br/veterinary/article/view/3977 DOI: http://dx.doi.org/10.5380/avs.v7i2.3977

GOLDSCHMIDT, M. H.; PEÑA, L.; ZAPPULLI, V. Tumors of the Mammary Gland. In: Meuten, D. J. Tumors in domestic animals. 5. Ed, p. 723 - 765, 2017.

GÓMEZ, B. J.; RAMÍREZ, M. R.; MALDONADO, J. E. Presence of lung metastases in bitches affected by malignant mammary neoplasms in Medellin (Colombia). Revista Medicina Veterinaria e Zootecnia Córdoba, v. 17, n. 2, p. 2983-2990, 2012. Disponível

em: http://www.scielo.org.co/scielo.php?script=sci_arttext\&pid=S012202682012000200005.

HIGGINS, R. J.; BOLLEN, A. W.; DICKINSON, P. J.; SISÓ-LLONCH, S. Tumors of the nervous system. In: MEUTEN, D.J. Tumors in domestic animals. 5. ed. lowa: lowa State Press, p. 737-738, 2017.

KOESTNER, A.; HIGGINS, R. J. Tumors of the nervous system. In: MEUTEN, D.J. Tumors in domestic animals. 4. ed. lowa: lowa State Press, p. 737-738, 2002.

KWIECIEN, J. M.; BASSEY-ARCHIBONG, B. I.; DABROWSKI, W.; RAYNER, L. G.; LUCAS, A. R.; DANIEL, J. M. Loss of Kaiso expression in breast cancer cells prevents intra-vascular invasion in the lung and secondary metastasis. Plos One. P. 1- 17, 2017. Disponível em: http://journals.plos.org/plosone/article?id=10.1371/journal.pone.0183883 DOI: https://doi.org/10.1371/journal.pone.0183883.

LABELLE, A.; LABELLE, P. Canine ocular neoplasia: a review. Veterinary Ophtalmology, v.16, supp.1, p.3-14, 2013.

MISDORP, W. Tumors of the mammary gland. In: MEUTEN, D.J. Tumors in domestic animals. 4. ed. lowa: lowa State Press, p. 575-606, 2002. 
PATSIKAS, M. N; DESSIRIS, A. The lymph drainage of the mammary glands in the bitch: a lymphographic study. Part I: The 1st, 2nd, 4th and 5th mammary glands. Anatomy Histology Embryology, v. 25, p.131-138, 1996.

QUEIROGA, F.; LOPES, C. Tumores mamários caninos: pesquisa de novos factores de prognóstico. Revista Portuguesa de Ciências Veterinárias, v. 97, n. 543, p. 119-127, 2002.

RASOTTO, R.; BERLATO, D.; GOLDSCHMIDT, M. H.; ZAPPULLI, V. Prognostic Significance of Canine Mammary Tumor Histologic Subtypes: An Observational Cohort Study of 229 Cases. Veterinary Pathology, V. 54, n.4, p. 571-578, 2017. Disponível em: http://journals.sagepub.com/doi/abs/10.1177/0300985817698208. DOI: $10.1177 / 0300985817698208$

RASOTTO, R.; ZAPPULLI, V.; CASTAGNARO, M.; GOLDSCHMIDT, M.H. A retrospective study of those histopathologic parameters predictive of invasion of the lymphatic system by canine mammary carcinomas. Veterinary Pathology, p. 330340, $2012 . \quad$ Disponível em: http://journals.sagepub.com/doi/abs/10.1177/0300985811409253. DOI: 10.1177/0300985811409253.

ROCHA, N. S; TOSTES, R. A. Diagnóstico comparativo entre citologia aspirativa por agulha fina e avaliação histológica da glândula mamária de cadelas. Colloquium Agrariae, v. 1, n.2, p. 38-42, 2005. Disponível em: http://revistas.unoeste.br/revistas/ojs/index.php/ca/article/viewArticle/104 DOI: 10.5747/ca.2005.v01.n2.a011.

ROUSSOS, E. T.; GOSWAMI, S.; BALSAMO, M.; WANG, Y.; STOBEZKI, R.; ADLER, E. Mena invasive (MenalNV) and Mena11a Isoforms play distinct roles in breast cancer cell cohesion and association with TMEM. Clinical \& Experimental Metastasis, V. 28, p. 515 - 527, 2011. Disponível em: https://link.springer.com/article/10.1007/s10585-011-9388-6 DOI: 10.1007/s10585011-9388-6.

SANTOS, A.J.; FRANCO, C.M.R.; BORGES, L.R.R.; MALHEIROS, S.M.F.; GABBAI, A.A. Metástases cerebrais. Revista Neurociências, v. 9, n.1, p.20-26, 2003.

SANTOS, R. L., ALESSI, A. C. Patologia Veterinária. 2 ed. Rio de Janeiro: Rocca p.842, 2017. 